\title{
Development of Postural Muscles and Their Innervation
}

\author{
J. IJkema-Paassen and A. Gramsbergen \\ Medical Physiology, University Medical Centre Groningen, the Netherlands
}

\begin{abstract}
Control of posture is a prerequisite for efficient motor performance. Posture depends on muscles capable of enduring contractions, whereas movements often require quick, forceful muscle actions. To serve these different goals, muscles contain fibers that meet these different tasks. Muscles with strong postural functions mainly consist of slow muscle fibers with a great resistance against fatigue. Flexor muscles in the leg and arm muscles are mainly composed of fast muscle fibers producing relatively large forces that are rapidly fatigable. Development of the neuromuscular system continues after birth. We discuss in the human baby and in animal experiments changes in muscle fiber properties, regression from polyneural into mononeural innervation, and developmental changes in the motoneurons of postural muscles during that period. The regression of poly-neural innervation in postural muscles and the development of dendrite bundles of their motoneurons seem to be linked to the transition from the immature into the adult-like patterns of moving and postural control.
\end{abstract}

Reprint requests to: J. IJkema-Paassen, Medical Physiology, A. Deusinglaan 1, bldg 3215, 9713 AV Groningen, the Netherlands; e-mail: j.ijkema-paassen@ med.rug.nl

\section{INTRODUCTION}

Movement of the extremities on the one hand and the maintenance of posture on the other require different properties of muscles. During standing and sitting, the postural muscles provide joint stiffness in order to resist gravity and to maintain balance. The muscles involved in these tasks require not only a long lasting resistance to fatigue because postures might have to be maintained for large parts of the day but also the possibility to contract quickly when sudden perturbations occur.

During walking, the abdominal and back muscles keep the trunk erect, and the antigravity muscles in the one leg provide stiffness, allowing the other leg to flex and swing. During the swing phase of the leg, the flexor muscles produce short and strong bursts, whereas the extensor muscles in this leg are flaccid. During standing, however, both the flexor and extensor muscles are active. To serve these different goals, namely the resistance to fatigue on the one hand and high contraction speed and large force production on the other, the trunk and leg muscles contain a specific mixture of slow, fatigue-resistant fibers, fast-fatigable fibers, and an intermediate-fiber type, which is fast but relatively fatigue resistant.

In 1678, Stefano Lorenzini described white and red muscles in the same animal and since then, the differences in color have been related to the metabolic and physiological properties of muscles. For an historical review on the identification of the different muscle-fiber types, see Dubowitz (1973). The properties of muscle fibers can be studied by recording the contraction speed of muscle fibers, 
by identifying the enzyme systems related to the metabolism in the muscle fiber, or by their type of myosin, the contractile protein.

When the nerve to a muscle is electrically stimulated (e.g. McPhedran et al., 1965; Wuerker et al., 1965) or a single motoneuron through intracellular micro-electrodes (e.g. Burke et al., 1973), a contraction of the muscle fiber occurs that can be measured by means of a force transducer. The time between the onset of the contraction and the peak value of tension is defined as the twitch contraction time. Such measurements indicate considerable differences in twitch contraction times among the muscle fibers. In the cat, contraction times vary between $20 \mathrm{~ms}$ for the fastest muscle fibers in the medial gastrocnemius and $130 \mathrm{~ms}$ for the slowest fibers in the soleus muscle (Burke et al., 1974). Fibers that reach the peak value relatively fast are called fast twitch or fast fibers, those that slowly build up the force are called slow twitch or slow fibers. In the human, twitch contraction times of the fibers of the extensor hallucis brevis muscle, for example, vary between $20 \mathrm{~ms}$ to $140 \mathrm{~ms}$, indicating that this foot muscle contains both slow and fast fibers (Sicca \& McComas, 1971).

Differences in muscle fibers can also be identified by their metabolism and morphology. Muscle fibers consist of thick myofilaments called myosin, surrounded by a hexagonal array of thin actin filaments. The myosin filament is an aggregate of around 100 myosin molecules, their 'tails' forming the filament. The 'heads' of the molecules, situated at an angle with their tails, form the cross bridges with the actin. Upon contraction, the cross bridges alter their angle with the myosin filament, giving a power stroke to the actin filament. For this process, ATP is used as the energy source. 'White' muscle fibers are dependent upon anaerobic metabolism and very little ATP is stored in them. Short-term replenishment of ATP is conducted via creatine phosphate, which transfers its phosphate group to ADP. When additional ATP is required, it will be derived from the anaerobic metabolism of glucose reserves in muscle fibers or of glucose from the blood. These fibers have a very high speed of contraction and a high myosin ATPase activity. ATP is used faster than it can be produced, thus these fibers fatigue rapidly.

'Red' fibers contain many mitochondria and acquire their energy from the aerobic metabolism of glucose and from free fatty acids. The glucose metabolism forms pyruvate, which enters the citric acid cycle in the mitochondria, as do the fatty acids. Red fibers have a low contraction speed and a low myosin ATPase activity. This property, in combination with a high production of ATP, explains why these fibers are fatigue resistant.

Enzyme-histochemical techniques make use of the differences in metabolism. Anaerobic and aerobic muscle fibers are respectively classified as type II or type I fibers. A further classification into type IIa and IIb can be made. Type IIa fibers are the intermediate fibers containing high contents of glycogen and mitochondrial enzymes and thus working under both anaerobic and aerobic conditions. The myosin ATPase technique has been used extensively to study fiber type distributions (Engel, 1962; Brooke \& Kaiser, 1970; Lind \& Kernell, 1991; IJkema-Paassen et al., 2001). Anaerobic and aerobic fibers differ in their sensitivity to the $\mathrm{pH}$ of the staining solutions, resulting in darker or lighter staining of the fibers.

Myosin ATPase resides in the heavy chain of myosin (Weiss et al., 1999). It has been established that the myosin has several isoforms (Pette \& Staron, 1990). Based on the differences in isoforms, antibodies against slow or fast myosin have been developed that can be visualized in histological sections. (Pette \& Staron, 1990, 2000; Canepari et al., 2000). Therefore, slow or type I fibers and fast or type II fibers can also be studied with the techniques mentioned above (Staron \& Pette, 1986; Bottinelli et al., 1991; 1994; Galler et al., 1994). 
Almost all muscles contain both slow and fast fibers. Percentages of slow and fast muscle fibers have been calculated in cross sections of muscles in the rat (Gramsbergen et al., 1996; IJkema-Paassen et al. al., 2001) and in the human (Johnson et al., 1973; Gollnick et al., 1974; Kumagai et al., 1984; Bellemare et al., 1986; Bottinelli \& Reggiani, 2000; Polla et al., 2004). From these studies, it became obvious that trunk muscles and extensor muscles in the legs in humans contain relatively large percentages of slow muscle fibers, whereas most other muscles are predominantly composed of fast muscle fibers. The percentages of type 1 muscle fibers are $57 \%$ in the $\mathrm{m}$. erector spinae, $46 \%$ in the $\mathrm{m}$. rectus abdominus, $54 \%$ in the $\mathrm{m}$. trapezius (an extensor), and $35 \%$ in the m.sternomastoid (a flexor). The m. soleus in the leg contains on average $88 \%$ type I fibers (Johnson et al., 1973).

\section{DEVELOPMENT OF MUSCLES AND DIFFERENTIATION OF MUSCLE FIBERS}

The skeletal muscles of vertebrates are derived from the paraxial mesoderm. This mesoderm develops into bilaterally paired somites at the end of the $5^{\text {th }}$ postmenstrual (PMA) week in the human embryo (Cossu et al., 1996; Larson, 2001a). The somites give rise to the muscles of the neck, trunk and limbs, and the axial skeleton. At the end of the $7^{\text {th }}$ week, the myotomes have developed, and then the muscles form by a process of fusion, splitting, or migration (for review see Mastaglia, 1981). Limb buds are formed from the lateral plate mesoderm, the upper limbs around the $38^{\text {th }}$ day PMA, and the lower limbs around the $43^{\text {rd }}$ day (Larson, 2001b). The limb buds consist of an ectodermal cap and the inner mesodermal core, giving rise to the skeleton, ligaments, and vasculature of the limbs. The mesenchymal cells located dorsally (the dorsal plate) later give rise to the flexors, whereas the cells in the ventral plate later on develop into the extensor muscles (FrancisWest et al., 2003)

The mesenchymal cells develop into myoblasts, and these mononucleated cells fuse with each other to form multinucleated myotubes. These so-called primary myotubes appear at about the $7^{\text {th }}$ week PMA and thereafter rapidly increase in number (Fenichel, 1966; Barbet et al., 1991). The innervation of the primary myotubes is observed from the $9^{\text {th }}$ week onward, the youngest age investigated (Fidzianska, 1980). This observation is in line with the data of Juntunen and Teräväinen (1972), who described the development of the myoneural junctions starting at age 8.6 weeks PMA in the intercostal muscles and at 10 weeks in the tibial muscle. The first general movements (movements in which all parts of the body are involved) can be observed between 8 and 10 weeks PMA, implying that the primitive myoneural junctions are functional by that time (de Vries et al., 1982) Secondary and subsequent generations of myotubes develop from undifferentiated mononucleated cells lying in close proximity to the primary myotubes (Ontell, 1977).

Much research on muscle development has been performed in rats, and most of the following results have been obtained in these animals. The primary myotubes, formed by the fusion of myoblasts, are already observed at embryonic day 9 (E9), and at E12 the nerves reach the myotubes (rats are born after a gestation period of 22 to 23 days); (Jansen \& Fladby, 1990; Wigmore \& Dunglison, 1998). The secondary myotubes develop beneath the basal lamina of the primary myotube, and as soon as the myotube has reached its tendons, an independent basal lamina is formed for the secondary myotube (Kelly \& Zacks, 1969; Ontell \& Kozeka, 1984; Duxson et al., 1986). Research in rodents and chick embryos has demonstrated that primary myotubes develop and differentiate even in the absence of innervation (Butler et al., 1982; Condon et al., 1988; 
1989; 1990). The appearance and development of secondary myotubes, on the other hand, seems to be dependent on innervation (Betz et al., 1980; Harris, 1981; McLennan, 1983; Ross et al., 1987a; 1987b). Shortly after their generation, the primary myotubes in fetal rats display immunoreactivity against slow myosin, whereas the secondary myotubes, emerging from E1 8 are immunoreactive to fast myosin (Rubinstein \& Kelly, 1981; Dhoot et al., 1985; Narusawa et al., 1987; Condon et al., 1989). These properties can change during development because from E15 onward, the superficially located primary myotubes of most muscles lose their reactivity to slow myosin and become reactive to fast myosin (Condon et al., 1989). In the human embryo, differences in the primary and secondary myotubes can be observed as early as 12 to 13 weeks PMA, using the myofibrillar ATPase method (Fenichel, 1966). Dreager and coworkers (1987) found that the primary myotubes in the quadriceps muscle at 10 to 12 weeks react with antibodies against slow myosin. At 14 to 15 weeks, secondary myotubes emerge and react with an antibody to fast myosin; this reaction similarly holds for a third wave of tertiary myotubes emerging at 16 to 17 weeks. During further development, the myotubes enlarge but by 33 to 36 weeks, around $50 \%$ of the secondary myotubes change their fast myosin into slow myosin (Dreager et al., 1987). Obviously, both in rats and in humans, rearrangements occur in the properties of part of the myotubes, but via different developmental trajectories.

At the end of the intra-uterine period, the number of myofilaments increases and the nucleus is pushed toward the cell membrane. From this moment, the fibers are called muscle fibers. In the human fetus, the change from myotubes into muscle fibers takes place around 22 weeks PMA (Mastaglia, 1981) Research in rats has indicated that during postnatal development, further changes occur in the properties of muscle fibers, mainly by changes in patterns of activation. The percentage of slow fibers in the rat's soleus muscle increases because the animal is beginning to use the muscle for support. Unloading the hindleg demonstrated that this development does not occur then (Lowrie et al., 1989; Sakuma et al., 1995). Reloading the soleus muscle for at least 2 weeks will undo the changes in properties of the muscle (Lee et al., 2004). In line with this evidence, the properties of the muscle fibers of the human baby are also subject to changes during the first years of life. The percentage of type I fibers in the diaphragm of preterm babies $(<37$ weeks) is around $10 \%$, increasing to $25 \%$ at term age and to $55 \%$ at 2 years of age. Similar changes were observed in the intercostal muscles. These muscles contain around $20 \%$ type I fibers in preterms, changing to $46 \%$ in full terms and to $65 \%$ in young children. (Keens et al., 1978; Deluca et al., 1986; Bottinelli \& Reggiani, 2000; Baldwin \& Haddad, 2002; Polla et al., 2004).

\section{DEVELOPMENT OF NEUROMUSCULAR INNERVATION}

The neuroepithelium in the ventricular zone of the neural tube in rats starts proliferating from embryonic day 12 (Nornes \& Das, 1974). The future motoneurons are the first neuroblasts to migrate toward ventrolateral positions in the developing spinal cord. Initially, these neuroblasts form a continuous column along the rostrocaudal extent of the spinal cord, and later on, after differentiation, motoneuronal pools develop. Axons of the motoneurons are the first to emerge from the spinal cord. Their initial guidance as far as axons to the trunk muscles are concerned depends on the sclerotomes of the somite (Keynes \& Stern, 1984; Hughes \& Salinas, 1999). The axons of the motoneurons heading for the muscles in the extremities form the spinal nerves. The 
dorsal ramus of these nerves head for the dorsal plate in the limb bud and the ventral ramus towards the ventral plate. From the dorsal plate, the flexor muscles develop and from the ventral plate the extensor muscles. The axons of a particular motoneuronal pool reach their muscles even after experimental perturbations at early developmental stages such as partial deletion and reversal of a spinal cord segment (Lance-Jones \& Landmesser, $1980 \mathrm{a} ; 1980 \mathrm{~b})$. Additionally, the experimental repositioning of muscle targets does not prevent correct connections being formed, indicating that both along the trajectory and by the target muscle, trophic factors are secreted that guide the outgrowing axons (Ebbens et al., 1996). In the human, an example of such specificity is observed in the Martin-Gruber anastomosis. The thumb is normally innervated by the median nerve but in the Martin-Gruber anastomosis, a crossover of some axons occurs from the median to the ulnar nerve. These nerves, however, still are able to locate their proper target muscle in the hand (McComas, 1996; Lee et al., 2005).

Upon contacting the muscle, synaptic transmission is established within 1 to 2 hours (Chow \& Cohen, 1983; Xie \& Poo, 1986). The nerve secretes agrin, a molecule that, after incorporation into the basal lamina of the muscle fibers, induces the aggregation of acetylcholine receptors (AChR) (Rupp et al., 1991; Bowe \& Fallon, 1995). Musclespecific kinase (MuSK), a tyrosine kinase receptor, is also activated by agrin and this, in turn, induces the nerve to stop growing, and then the growth cone changes into a presynaptic nerve terminal (Valenzuela et al., 1995; DeChiara et al., 1996; Gautam et al., 1996). In the human embryo, the first primitive motor endplates are observed at around 9 weeks PMA in the quadriceps femoris (Fidzianska, 1980), intercostals, and tibial muscles (Jutunen \& Teräväinen, 1973).

The motor endplates are initially innervated by axonal branches from different motoneurons. This so-called polyneural innervation has been studied in rats by intracellular recordings of endplate potentials in response to a graded stimulation of the muscle nerve (Redfern, 1970). With increasing stimulus intensity, more and more axons are recruited, leading to a stepwise increase of the endplate potentials. The number of these steps in the endplate potential indicates the number of axons innervating the muscle fiber. In rats, the numbers of axons impinging on one muscle fiber can vary from two axons in lumbrical muscles (Betz et al., 1979) to six axons in the soleus muscle (Bennet \& Pettigrew, 1974). The maximum in polyneural innervation is reached one day before birth in the diaphragm and the intercostal muscles (Bennet \& Pettigrew, 1974) and a few days after birth in the soleus and the extensor digitorum muscle (Balice-Gordon \& Thompson, 1988; Brown et al., 1976).

Additionally, the period of time in which polyneural innervation is replaced by mononeural innervation differs among the various muscles. The rat's extensor digitorum muscle is already mononeurally innervated from the third day of life (Balice-Gordon \& Thompson, 1988), whereas in the soleus and psoas muscle polyneural innervation lasts until the third week (Brown et al., 1976; IJkema-Paassen \& Gramsbergen, 1998).

The regression of polyneural innervation probably is related to muscle activity. Electrical or pharmacological stimulation of the soleus muscle accelerates the process of regression (O'Brien et al., 1978; Thompson, 1983; Vrbova et al., 1988; Zu \& Vrbova, 1992; Vyskocil \& Vrbova, 1993), whereas a decrease in activity by tendinotomy of the Achilles' tendon, nerve conduction block, or blocking synaptic transmission results in a retarded regression of polyneural innervation (Benoit \& Changeux, 1975; Thompson \& Jansen, 1977; Riley, 1978; Brown et al., 1982; Duxson, 1982; Caldwell \& Ridge, 1983; Callaway \& Van Essen, 1989; Greensmith \& Vrbova, 1991).

Probably the activity in the muscle fibers 
releases $\mathrm{K}^{+}$that accumulates in the synaptic cleft and induces an increase of $\mathrm{Ca}^{2+}$ in the nerve terminal. When surpassing a certain level, $\mathrm{Ca}^{2+}$ activates the neural protease calpain (CANP), which in turn leads to the breakdown of cytoskeletal proteins and the subsequent degradation of the supernumerary nerve endings (Vrbova et al., 1995). Small nerve terminals take the lead in this withdrawal because the accumulation of $\mathrm{Ca}^{2+}$ reaches its critical concentration more easily. It has been suggested that slow muscle fibers are more heavily innervated than fast fibers (Jansen \& Fladby, 1990). Indeed, primary myotubes, the precursors of slow muscle fibers, are innervated by many more nerve endings than are secondary myotubes (Sheard et al., 1991). These findings indicate that polyneural innervation is also a prominent feature in postural muscles in their initial stages of development, as they contain a large percentage of type I fibers (for review see Ribchester, 2001).

Polyneural innervation for certain muscles persists in the postnatal period, whereas in other muscles, regression is completed at the day of birth. The regression of polyneural innervation in the diaphragm and intercostal muscles is complete at the day of birth, at the onset of continuous respiration (Bennet \& Pettigrew, 1974), whereas the end of polyneural innervation in the soleus muscle of the rat coincides with the emergence of the adult type of walking (Brown et al., 1976; Westerga \& Gramsbergen 1990; Geisler et al., 1993). This seems to indicate a relation with the function of the muscles.

Only limited knowledge is available on polyneural innervation and its regression in the human. Fidzianska (1980) studied in fetuses until 20 weeks PMA the ultrastructural pattern of the early stages of end-plate formation in the quadriceps femoris muscle. She observed polyneural innervation until 20 weeks PMA. Unfortunately, this stage did not extend until older ages. The regression of poly- neural innervation was studied in the psoas muscle in human fetuses from 15.5 weeks PMA and in babies until 80 weeks PMA (Gramsbergen et al., 1997). The psoas muscle is important for stabilizing the vertebral column and leg adduction and thus is involved in postural control. The end stage of polyneural innervation in this muscle was reached at the age of 12 weeks post term, a few months ahead of the age at which sitting is developing.

\section{DEVELOPMENTAL CHANGES IN MOTONEURONS INNERVATING POSTURAL MUSCLES}

The motoneurons innervating postural and anti-gravity muscles, at adult age, are coupled by dendrite bundles. With the Golgi technique, a silver impregnation technique for staining neurons, these dendrite bundles have been observed in the spinal cord of rats and cats (Cajal, 1911; Scheibel \& Scheibel, 1970; Anderson et al., 1976; Roney et al., 1979; Schroder, 1980; Nicoulopoulos-Stournaras \& Iles, 1983; Furicchia \& Goshgarian, 1987; Bellinger \& Anderson, 1987a; 1987b; Anderson et al., 1988). Remarkably, in rats at early postnatal ages, the motoneurons innervating the soleus muscle had their dendrites still running in all directions. From postnatal day 14 (P14) until P16, the dendrites reorganized into bundles (Westerga \& Gramsbergen, 1992). The age at which this reorganization occurred in the soleus muscle coincided with the point at which rats start to walk fluently in an adult like fashion (Westerga \& Gramsbergen, 1990).

No such reorganizations have been found in the tibialis anterior muscle, a hind limb flexor. In later research, we studied the occurrence of dendrite bundles in a large variety of muscles in the trunk and in extremities. We demonstrated that dendrite bundles are observed only in the dendrites 
of motoneurons innervating antigravity muscles and trunk muscles (Gramsbergen et al., 1996). Further results indicated that such reorganization is not dependent upon contacts with muscles or segmental afferent input but rather upon descending influences. Spinal cord transection prevented this reorganization from occurring (Gramsbergen et al., 1995).

Dendrite bundles have also been observed in the human spinal cord (Schoenen, 1982). Schoenen found dendrite bundles to be the tightest in the ventromedial motoneuronal column, in which motoneurons are located innervating the axial muscles, and in the central column with motoneurons innervating extensor muscles of leg and thigh.

Later research showed that the dendrites in dendrite bundles are interconnected by means of gap junctions (van der Want et al., 1998). The junctions enable the transmission of ionic currents and play a role in electrotonic coupling of the motoneurons. These dendrodendritic connections therefore might play a role in synchronizing the activity of the motoneurons to antigravity and trunk muscles. The coincidence of their development and the onset of fluent walking, as well as their dependency on the integrity of descending fiber projections, suggest a causal relation with postural control mechanisms in the central nervous system (Farmer, 1998).

\section{CONCLUSION}

Research in the human and in the rat indicates that the development of the muscles and their innervation continues after birth. Changes in the myosin composition of muscle fibers result from changes in the activity of the muscles. Activity is also of great importance for the regression of polyneural innervation. The formation of dendrite bundles, on the other hand, is not related to activity but rather to connections with supraspinal systems. When activity is reduced or completely halted at an early stage, we know from animal experiments that this leads to abnormalities in myosin composition in the muscles and a delayed regression of polyneural innervation. When extrapolating these results to the human situation, we hypothesize that abnormal motor and postural control in babies resulting from complications in the perinatal period can induce abnormal fiber type compositions in the affected muscles and deviances in the development of mononeural innervation patterns.

\section{REFERENCES}

Anderson WJ, Stromberg MW, Hinsman EJ. 1976. Morphological characteristics of dendrite bundles in the lumbar spinal cord of the rat. Brain Res 110: 215-227.

Anderson WJ, Bellinger DL, Lorton D. 1988. Morphology of dendrite bundles in the cervical spinal cord of the rat: A light microscopic study. Exp Neurol 110: 121-138.

Baldwin KM, Haddad F. 2002. Skeletal muscle plasticity: cellular and molecular responses to altered physical activity paradigms. Am J Phys Med Rehabil 81 suppl: S40-S51.

Balice-Gordon RJ, Thompson WJ. 1988. Synaptic rearrangements and alterations in motor unit properties in neonatal rat extensor digitorum longus muscle. J Physiol (Lond) 398: 191-210.

Barbet JP, Thornell LE, Butler-Browne GS. 1991. Immunocytochemical characterization of two generations of fibers during the development of the human quadriceps muscle. Mech Dev 35: 3-11.

Bellemare F, Bigland-Ritchie B, Woods JJ. 1986. Contractile properties of the human diaphragm in vivo. J Appl Physiol 61: 1153-1161.

Bellinger DL, Anderson WJ. 1987a. Postnatal development of cell columns and their associated dendrite bundles in the rat. I: The ventrolateral cell column. Dev Brain Res 35: 55-67.

Bellinger DL, Anderson WJ. 1987b. Postnatal development of cell columns and their associated dendrite bundles in the rat. II: The ventromedial cell column. Dev Brain Res 35: 69-82. 
Bennet MR, Pettigrew AG. 1974. The formation of synapses in striated muscle during development. $J$ Physiol (Lond) 241: 515-545.

Benoit P, Changeux J-P. 1975. Consequences of tenotomy on the evolution of multi-innervation in developing rat soleus muscle. Brain Res 99: 351-358.

Betz WJ, Caldwell JH, Ribchester RR. 1979. The size of motor units during post-natal development of rat lumbrical muscle. J Physiol (Lond) 297: 463-478.

Betz WJ, Caldwell JH, Ribchester RR. 1980. The effects of partial denervation at birth on the development of muscle fibres and motor units in rat lumbrical muscle. J Physiol (Lond) 303: 265-279.

Bottinelli R, Schiafinno S, Reggiani C. 1991. Forcevelocity properties and myosin light chain isoform compositions of skinned fibres from rat skeletal muscle. J Physiol (Lond) 437: 655-672.

Bottinelli R, Betto R, Schiafinno S, Reggiani C. 1991. Maximum shortening velocity and co-existence of myosin heavy chain isoforms in single skinned fast fibres of rat skeletal muscle. J Muscle Res Cell Motil 15: 413-419.

Bottinelli R, Reggiani C. 2000. Human skeletal muscle fibres: molecular and functional diversity. Prog Biophys Mol Biol 73: 195-262.

Bowe MA, Fallon JR. 1995. The role of agrin in synapse formation. Ann Rev Neurosc 18: 443-462.

Brooke MH, Kaiser KK. 1970. Muscle fibre types: how many and what kind? Arch Neurol 23: 369-379.

Brown MC, Jansen JKS, Van Essen D. 1976. Polyneuronal innervation of skeletal muscle in new-born rats and its elimination during maturation. J Physiol (Lond) 261: 387-422.

Brown MC, Hopkins WG, Keynes RJ. 1982. Comparison of effects of denervation and botulinum toxin paralysis on muscle properties in mice. $\mathbf{J}$ Physiol (Lond) 327: 29-37.

Burke RE, Levine DN, Tsairis P, Zajac, FE. 1973. Physiological types and histochemical profiles in motor units of the cat gastrocnemius. J Physiol (Lond) 234: 723-748.

Burke RE, Levine DN, Tsairis P, Zajac FE. 1974. Motor units in cat soleus muscle: Physiological, histochemical and morphological characteristics. J Physiol (Lond) 238: 503-514.

Butler J, Cosmos E, Brierly J. 1982. Differentiation of muscle fibre types in aneurogenic brachial muscles in the chick embryo. J Exp Zool 224: 65-80.

Cajal S. 1911. Histologie du système nerveux de l'homme et des vertebrés. Maloine, Paris.
Caldwell JH, Ridge RMAP. 1983. The effects of deafferentation and spinal cord transection on synapse elimination in developing rat muscles. $\mathrm{J}$ Physiol (Lond) 339: 145-159.

Callaway EM, van Essen DC. 1989. Slowing of synaps elimination by alpha-bungarotoxin super-fusion of the neonatal rabbit soleus muscle. Dev Biol 131: 356-365.

Canepari M, Rossi R, Pellegrino MA, Bottinelli R, Schiaffino S, Reggiani C. 2000. Functional diversity between orthologous myosins with minimal sequence diversity. J Muscle Res Cell Motil: 375-382.

Chow I, Cohen MW. 1983. Developmental changes in the distribution of acetylcholine receptors in the myotomes of Xenopus laevis. J Physiol (Lond) 339: 553-571.

Condon K, Thompson WH, Siberstein L, Blau HM. 1988. Fibre type differentiation during rat hind limb myogenesis does not depend on innervation. Soc Neurosci Abstr 14; 163.

Condon KW, Soileau LC, Silberstein L, Blau HM, Thompson WJ. 1989. Development and innervation of muscle fiber types in the rat hindlimb. In: Landmesser, L, ed, The Assembly of the Nervous System. New York, NY, USA: Alan R. Liss; 5163.

Condon K, Silberstein L, Blau HM, Thompson WJ. 1990. Differentiation of fiber types in aneural musculature of the prenatal rat hindlimb. Dev Biol 138: 275-295.

Cossu G, Tajbakhsh S, Buckingham M. 1996. How is myogenesis initiated in the embryo? Trends Genet 12: 218-223.

DeChiara TM, Bowen DC, Valenzuela DM, Simmons MV, Poueymirou WT, Thomas S, et al., 1996. The receptor tyrosine kinase, MuSK, is required for neuromuscular junction formation in vivo. Cell 85 : 501-512.

Deluca CJ, Sabbahi MA, Roy SH. 1986. Median frequency of the myoelectric signal effects of hand dominance. Eur J Appl Physiol 55: 457-464.

de Vries JIP, Visser GHA, Prechtl HFR. 1982. The emergence of fetal behaviour. I. Qualitative aspects. Early Hum Dev 7: 301-322.

Dhoot GK, Hales MC, Grail BM, Perry SV.1985. The isoforms of $\mathrm{C}$ protein and their distribution in mammalian skeletal muscle. J Muscle Res Cell Motil 6: 487-505.

Dreager A, Weeds AG, Fitzsimons RB. 1987. Primary, 
secondary and tertiary myotubes in developing skeletal muscle: A new approach to the analysis of human myogenesis. J Neurol Sci 81: 19-43.

Dubowitz V, Brooke MH, Nerville HE. 1973. Muscle biopsy: a modern approach. In: Walton $\mathrm{JN}$, ed, Major Problems in Neurology. London, UK: W.B. Saunders; 44-49.

Duxson MJ. 1982. The effect of postsynaptic block on development of the neuromuscular junction in postnatal rats. J Neurocytol 11: 395-408.

Duxon MJ, Ross JJ, Harris AJ. 1986. Transfer of differentiated synaptic terminals from primary myotubes to new-formed muscle cells during embryonic development in the rat. Neurosci Lett 71: 147-152.

Ebens A, Brose K, Leonardo ED, Hanson, MG, Bladt F, Birchmeier C, et al. 1996. Hepatocyte growth factor/scatter factor is an axonal chemoattractant and a neurotrophic factor for spinal motoneurons. Neuron 17: 1157-1172.

Engel WK. 1962. The essentiality of histo- and cytochemical studies of skeletal muscle in the investigation of neuromuscular disease. Neurology 12: 778-784.

Farmer SF, 1998. Rhythmicity, synchronization and binding in human and primate motor systems. $\mathbf{J}$ Physiol 509: 3-14.

Fenichel GM. 1966. A histochemical study of developing human skeletal muscle. Neurol 16: 741745.

Fidzianska A. 1980. Human Ontogenesis II. Development of the human neuromuscular junction. $J$ Neuropathol Exp Neurol 39: 606-615.

Francis-West PH, Antoni L, Anakwe K. 2003. Regulation of myogenetic differentiation in the developing limb bud. J Anat 202: 69-81.

Furicchia JV, Goshgarian HG. 1987. Dendritic organisation of phrenic motoneurons in the adult rat. Exp Neurol 96: 621-634.

Galler S, Schmitt T, Pette, D. 1994. Stretch activation, unloaded shortening velocity, and myosin heavy chain isoforms of rat skeletal muscle fibres. J Physiol (Lond) 478: 523-531.

Gautam M, Noakes PG, Moscoso L, Rupp F, Scheller RH, Merlie JP, et al. 1996. Defective neuromuscular synaptogenesis in agrin-deficient mutant mice. Cell 85: 525-535.

Geisler HC, Westerga J, Gramsbergen A. 1993. Development of posture in the rat. Acta Neurobiol Exp 53: 517-523.
Gollnick PD, Sjodin B, Karlsson J, Jansson E, Salting B. 1974. Human soleus muscle: A comparison of fiber composition and enzyme activities with other leg muscles. Pflügers Archiv 348: 247-255.

Gramsbergen A, IJkema-Paassen J, Klok F. 1995. Factors influencing the development of dendrite bundles in the rat's spinal cord. Soc Neurosci Abstr $21 ; 705$.

Gramsbergen A, IJkema-Paassen J, Westerga J, Geisler HC. 1996. Dendrite bundles in moto-neuronal pools of trunk and extremity muscles in the rat. Exp Neurol 137: 34-42.

Gramsbergen A, IJkema-Paassen J, Nikkels PGJ, Hadders-Algra M. 1997. Regression of polyneural innervation in the human psoas muscle. Early Hum Devel 49: 49-61.

Greensmith L, Vrbova G. 1991. Neuromuscular contacts in the developing rat soleus depend on muscle activity. Dev Brain Res 62: 121-129.

Harris AJ. 1981. Embryonic growth and innervation of rat skeletal muscles I. Neural regulation of muscle fibre numbers. Phil Trans R Soc Lond 293: 257 277.

Hughes SM, Salinas PC. 1999. Control of muscle fibre and motoneuron diversification. Curr Opin Neurobiol 9: 54-64.

IJkema-Paassen J, Gramsbergen A. 1998. Polyneural innervation in the psoas muscle of the developing rat. Muscle Nerve 21: 1058-1063.

IJkema-Paassen J, Meek MF, Gramsbergen A. 2001. Muscle differentiation after sciatic nerve transection and reinnervation in adult rats. Ann Anat 183:369-77

Jansen JKS, Fladby T. 1990 . The perinatal reorganization of the innervation of skeletal muscles in mammals. Prog Neurobiol 34: 39-90.

Johnson MA, Polgar J, Weightman D, Appleton D. 1973. Data on the distribution of fibre types in thirty-six human muscles. J Neurol Sci 18: 111129.

Juntunen J, Terävåinen H. 1973. Effect of prolonged nerve blockage on the development of the myoneural junction. Acta Physiol Scand 87: 344-347.

Keens TG, Bryan AC, Levinson H, Ianuzzo CD. 1978. Developmental pattern of muscle fiber types in human ventilatory muscles. J Appl Physiol 44: 909-913.

Kelly AM, Zacks SI. 1969. The histogenesis of rat intercostal muscle. J Cell Biol 42: 135-153.

Keynes RJ, Stern CD. 1984. Segmentation in the 
vertebrate nervous system. Nature (London) 310: 786-789.

Kumagai $T$, Hakamada $S$, Hara $K$, Takeuchi $T$, Miyazaki S. 1984. Development of human fetal muscles: a comparative histochemical analysis of the psoas and the quadriceps muscles. Neuroped 15: 198-202.

Lance-Jones C, Landmesser LT. 1980a. Motoneuron projection patterns in embryonic chick limbs following partial deletions of spinal cord. J Physiol (Lond) 302: 559-580.

Lance-Jones C, Landmesser LT. 1980b. Motoneuron projection patterns in the chick hindlimb following early partial reversals of the spinal cord. J Physiol (Lond) 302: 581-602.

Larson WJ. 2001a. The third week. In: Larson WJ, ed, Human Embryology. Philadelphia, Pennsyl-vania, USA: Churchill Livingston; 53-78.

Larson WJ. 2001b. Development of the limbs. In; Larson WJ, ed, Human Embryology. Philadelphia, Pennsylvania, USA: Churchill Livingston; 315-348.

Lee KS, Oh CS, Chung IH, Sunwoo IN. 2005. An anatomic study of the Martin-Gruber anastomosis: electrodiagnostic implications. Muscle Nerve 31: 95-97.

Lee K, Lee YS, Lee M, Yamashita M, Choi I. 2004. Mechanics and fatigability of the rat soleus muscle during early reloading. Yonsei Med J 45: 690-702.

Lind A, Kernell D. 1991. Myofibrillar ATPase histochemistry of rat's skeletal muscles: a 'two dimensional' quantitative approach. J Histochem Cytochem 39: 589-597.

Lowrie MB, More AF, Vrbova G. 1989. The effect of load on the phenotype of the developing rat soleus muscle. Pflugers Arch 41 5: 204-208.

Mastaglia FL. 1981. Growth and development of the skeletal muscles. In: Davis JA, Dobbing J, eds. Scientific Foundations of Paediatrics, IInd ed. London, UK: Heinemann Limited; 590-620.

McComas AJ. 1996. Development of muscle innervation. In: McComas AJ, ed, Skeletal muscle Form and Function. United Kingdom: Human Kinetics; 77-89.

McLennan IS. 1983. Neural dependence and independence of myotube production in chicken hindlimb muscles. Dev Biol 98: 287-294.

McPhedran AM, Wuerker RB, Henneman E. 1965. Properties of motor units in a homogeneous red muscle (soleus) of the cat. J Neurophysiol 28: 71-84.

Narusawa M, Fitzsim ons RB, Izumo S, Nadal-Ginard B,
Rubinstein NA, Kelly AM. 1987. Slow myosin in developing rat skeletal muscle. J Cell Biol 104: 447-459.

Nicoulopoulos-Stournaras S, Iles JF. 1983. Motor neuron columns in the lumbar spinal cord of the rat. J Comp Neurol 217: 75-85.

Nornes HO, Das GD. 1974. Temporal pattern of neurogenesis in spinal cord of rat. I. An autoradiographic study - time and sites of origin and migration and settling patterns of neuroblasts. Brain Res 73: 121-138.

O'Brien RAD, Ostberg AJ, Vrbova G. 1978. Observations on the elimination of polyneural innervation in developing mammalian skeletal muscle. J Physiol (Lond) 282: 571-582.

Ontell M. 1977. Neonatal muscle: an electron microscopic study. Anat Rec189: 669-690.

Ontell M, Kozeka K. 1984. The organogenesis of murine striated muscle: a cytoarchitectural study. Am J A nat 171: 133-148.

Pette D, Staron RS. 1990. Cellular and molecular diversities of mammalian skeletal muscle fibers. Rev Physiol Biochem Pharmacol 16: 1-76.

Pette D, Staron RS. 2000. Myosin isoforms, muscle fiber types, and transitions. Microsc Res Techn 50: 500-509.

Polla B, D'Antona G, Bottinelli R, Reggiani C. 2004. Respiratory muscle fibres: specialisation and plasticity. Thorax 59: 808-817.

Ribchester RR. 2001. Development and plasticity of neuromuscular innervation. In: Kalverboer AF, Gramsbergen A, eds, Handbook of Brain and Behaviour in Human Development. Dordrecht, The Netherlands: Kluwer Academic Publishers; 261342.

Riley DA. 1978. Tenotomy delays the postnatal development of the motor innervation of the rat soleus. Brain Res 143: 162-170.

Redfern PA. 1970. Neuromuscular transmission in newborn rats. J Physiol (Lond) 209: 701-709.

Roney KJ, Scheibel AB, Shaw GL.1979. Dendritic bundles: Survey of anatomical experiments and physiological theories. Brain Res Rev 1: 225-271.

Ross JJ, Duxson, MJ, Harris AJ. 1987a. Formation of primary and secondary myotubes in rat lumbrical muscles. Development 100: 383-394.

Ross JJ, Duxson MJ, Harris AJ. 1987b. Neural determination of muscle fibre numbers in embryonic rat lumbrical muscles. Development 100: 395-409. 
Rubinstein NA, Kelly AM. 1981. Development of muscle fiber specialization in the rat hindlimb. $J$ Cell Biol 90: 128-144.

Rupp F, Payan DG, Magill-Solc C, Cowan DM, Acheller RH. 1991. Structure and expression of a rat agrin. Neuron 6: 811-823.

Sakuma K, Yamaguchi A, Ohmori H, Katsuta S. 1995. Nonuniform changes in fibre types in the soleus muscle of the developing rat. Eur J Appl Physiol Occup Physiol 72: 132-137.

Scheibel ME, Scheibel AB. 1970. Organization of spinal motoneuron dendrites in bundles. Exp Neurol 28: 106-112.

Schoenen J. 1982. Dendritic organization of the human spinal cord: The motoneurons. J Comp Neurol 211: 226-247.

Schroder HD. 1980. Organization of the motoneurons innervating the pelvic muscles of the male rat. J Comp Neurol 192: 567-587.

Sheard PW, Duxson MJ, Harris J. 1991. Neuromuscular transmission to identified primary and secondary myotubes: a reevaluation of polyneural innervation patterns in rat embryos. Dev Biol 148: 459-472.

Sicca RE, McComas AJ. 1971. Fast and slow twitch units in a human muscle. J Neurol Neurosurg Psych 34: 113-120.

Staron RS, Pette D. 1986. Correlation between myofibrillar ATPase activity and myosin heavy chain composition in rabbit muscle fibers. Histochemistry 86: 19-23.

Thompson W. 1983. Synapse elimination in neonatal rat muscle is sensitive to pattern of muscle use. Nature 302: 614-616.

Thompson W, Jansen JK. 1977. The extent of sprouting of remaining motor units in partly denervated immature and adult rat soleus muscle. Neuroscience 2: 523-535.

Van der Want JJL, Gramsbergen A, IJkema-Paassen J, de Weerd H, Liem RSB. 1998. Dendro-dendritic connections between motoneurons in the rat spinal cord: an electron microscopic investi-gation. Brain
Res 779: 342-345.

Valenzuela DM, Stitt TN, DiStefano PS, Rojas E, Mattsson K, Compton DL, et al. 1995. Identification of a receptor tyrosine kinase specific for the skeletal muscle lineage: expression in embryonic muscle, at the neuromuscular junction and after injury. Neuron 15: 573-584.

Vrbova G, Lowrie MB, Evers J. 1988. Reorgani-zation of synaptic inputs to developing skeletal muscle fibers. Ciba Foundation Symposia 138: 131-151.

Vrbova G, Gordon T, Jones R: 1995. Emergence of the mammalian motor unit. In: Vrbova $G$, Gordon $T$, Jones $\mathrm{R}$, eds, Nerve-Muscle interaction. London, UK: Chapman and Hall; 93-107.

Vyskocil F, Vrbova G. 1993. Nonquantal release of acetylcholine affects polyneuronal innervation on developing rat muscle fibers. Eur J Neurosci 5: 1677-1683.

Weiss A, Schiaffino S, Leinwand LA.1999. Comparative sequence analysis of the complete human sarcomeric myosin heavy chain family: implications for functional diversity. J Mol Biol 290: 6175.

Westerga J, Gramsbergen A. 1990. Development of locomotion in the rat. Dev Brain Res 57: 163-174.

Westerga J, Gramsbergen A. 1992. Structural changes of the soleus and tibial anterior motoneuron pool during development. J Comp Neurol 316: 406-416.

Wigmore PM, Dunglison GF. 1998. The generation of fiber diversity during myogenesis. Intern J Dev Biol 42: 117-125.

Wuerker RB, McPhedran AM, Henneman E. 1965. Properties of motor units in a heterogeneous pale muscle (m.gastrocnemius) of the cat. J Neurophysiol 28: 85-99.

Xie ZP, Poo MM. 1986. Initial events in the formation of neuromuscular synapse: rapid induction of acetylcholine release from embryonic neuron. Proc Nat Acad Sci USA 83: 7069-7073.

Zhu PH, Vrbova G. 1992. The role of $\mathrm{Ca}_{-2}^{+}$in the elimination of polyneuronal innervation of rat soleus muscle fibres. Eur J Neurosci 4: 433-437. 

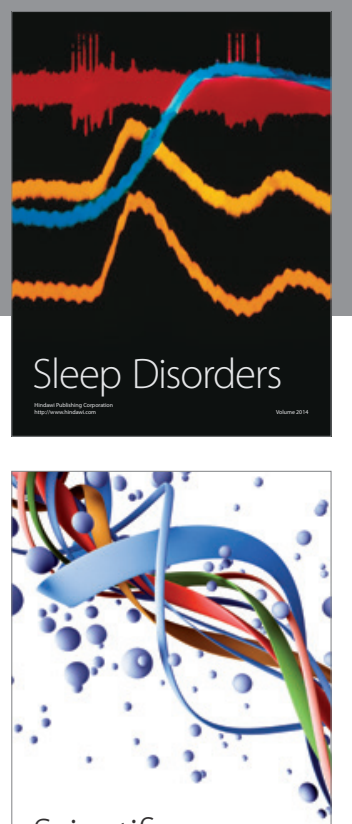

Scientifica
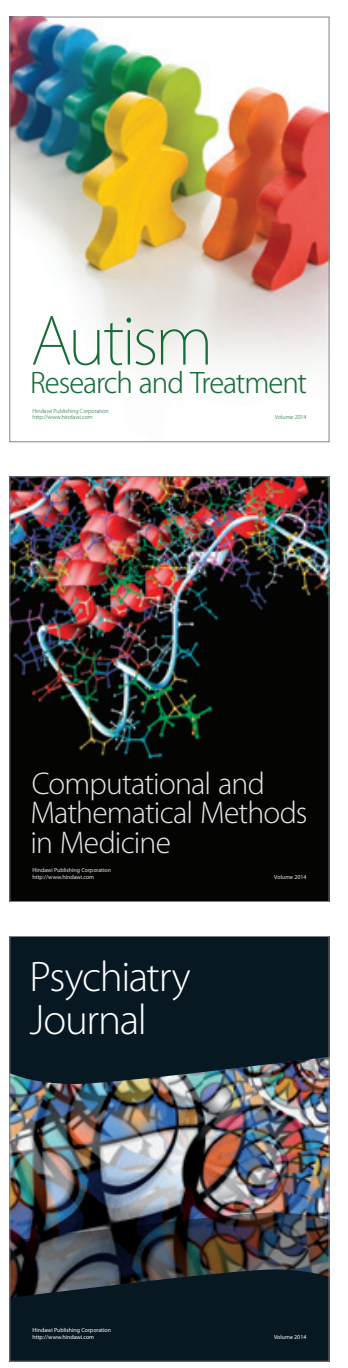
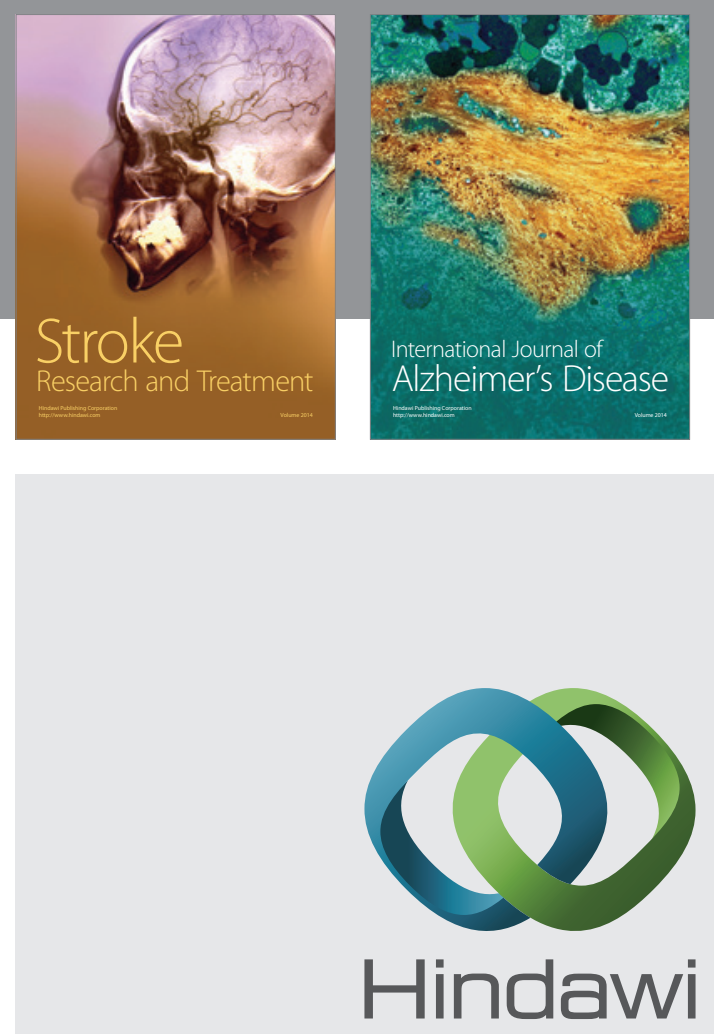

Submit your manuscripts at

http://www.hindawi.com
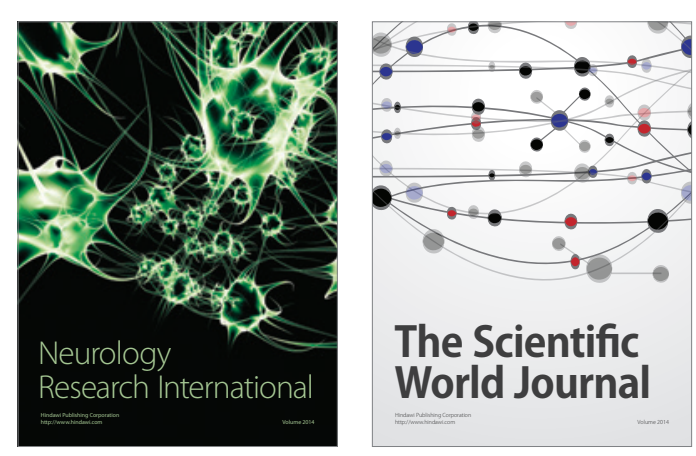

The Scientific World Journal

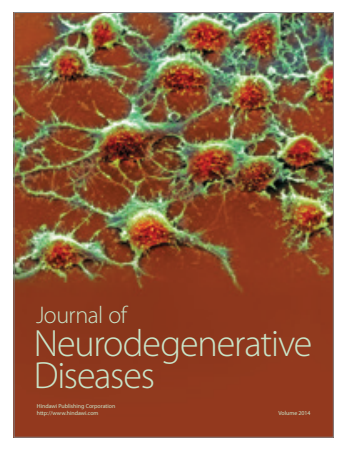

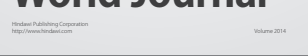

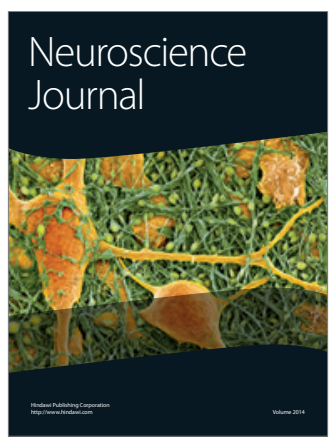

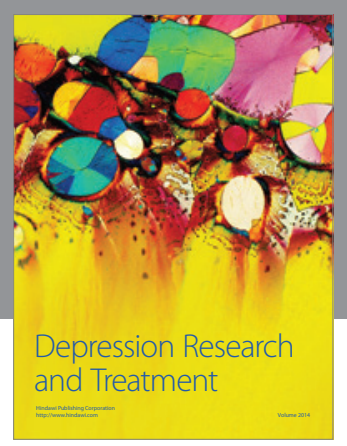
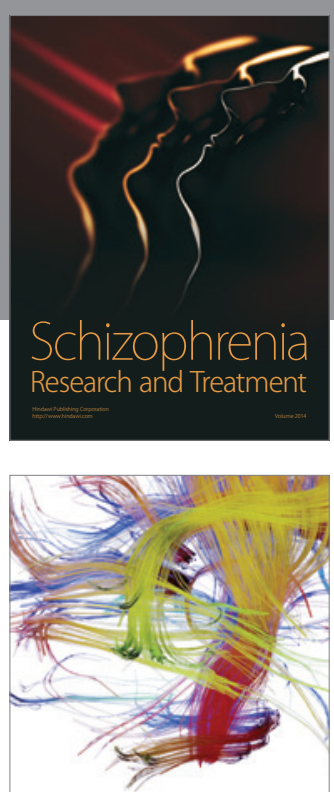

Brain Science

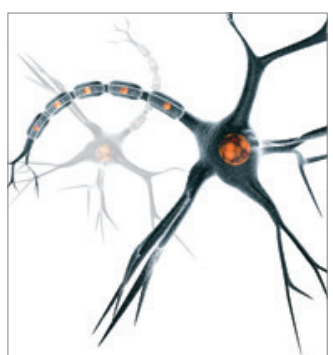

Neural Plasticity
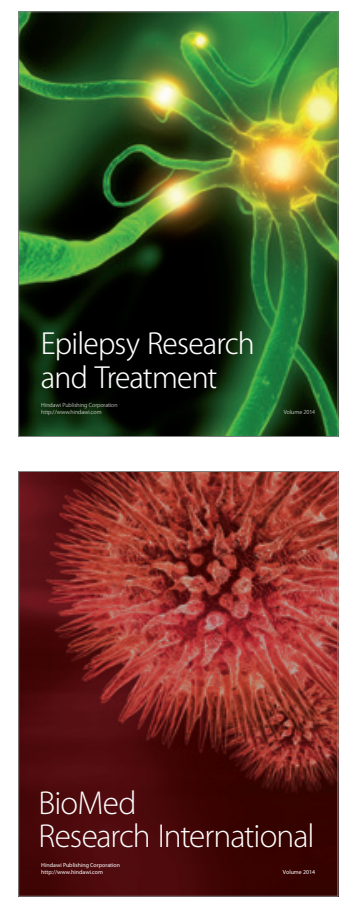

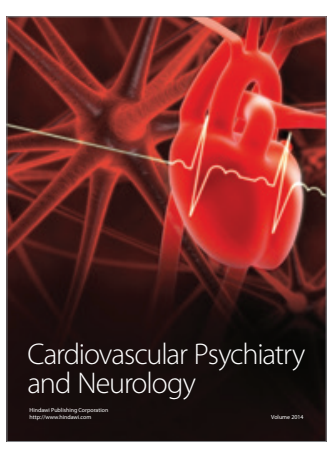

Parkinson's

Disease
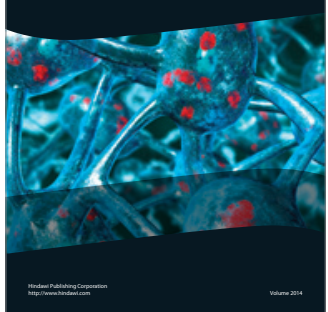